4. Linde K, Kriston L, Rücker G, et al. Efficacy and acceptability of pharmacological treatments for depressive disorders in primary care: systematic review and network meta-analysis. Ann Fam Med. 2015;13(1):69-79.

5. Linde K, Sigterman K, Kriston L, et al. Effectiveness of psychological treatments for depressive disorders in primary care: systematic review and meta-analysis. Ann Fam Med. 2015;13(1):56-68.

6. van Dijk W, Tan W, Li P, et al. Clinical relevance of fixed ratio vs lower limit of normal of $\mathrm{FEV}_{1} / \mathrm{FVC}$ in COPD: patient-reported outcomes from the CanCOLD cohort. Ann Fam Med. 2015;13(1):41-48.

7. Casado V, Navarro SM, Alvarez AE, Villafañe M, Miranda A, Spaans N. Laryngeal measurements and diagnostic tools for diagnosis of chronic obstructive pulmonary disease. Ann Fam Med. 2015;13(1):49-52.

8. Ottenheijm RPG, Cals JWL, Weijers R, Vanderdood K, de Bie R, Dinant G-J. Ultrasound imaging for tailored treatment of patients with acute shoulder pain. Ann Fam Med. 2015;13(1):53-55.

9. Angier H, Hoopes M, Gold R, et al. An early look at rates of uninsured safety net clinic visits after the Affordable Care Act. Ann Fam Med. 2015;13(1):10-16.
10. Green LA, Potworowski G, Day A, et al. Sustaining "meaningful use" of health information technology in low-resource practices. Ann Fam Med. 2015;13(1):17-22.

11. Rehm J, Allamani A, Della Vedova R, et al. General practitioners recognizing alcohol dependence: a large cross-sectional study in 6 European countries. Ann Fam Med. 2015;13(1):28-32.

12. Stabenau HF, Morrison L, Gahbauer E, Leo-Summers L, Allore H, Gill TM. Functional trajectories in the year before hospice. Ann Fam Med. 2015;13(1):33-40.

13. King VJ, Fontaine PL, Atwood LA, et al. Clinical practice guideline executive summary: labor after cesarean/planned vaginal birth after cesarean. Ann Fam Med. 2015;13(1):80-81.

14. Mackey TK, Liang BA. It's time to shine the light on direct-toconsumer advertising. Ann Fam Med. 2015;13(1):82-85.

15. Rosenblatt RA, Andrilla CA, Catlin M, Larson EH. Geographic and specialty distribution of physicians trained to provide office-based treatment of opioid use disorder in the United States. Ann Fam Med. 2015;13(1):23-26.

\title{
EDITORIAL
}

\section{Treatment of Depression in Primary Care}

\author{
Frank V. deGruy, MD, MSFM \\ University of Colorado School of Medicine, Denver, Colorado
}

Ann Fam Med 2015;13:3-5. doi: 10.1370/afm.1726.

$\mathrm{I}$ $n$ the world of primary care, we have been struggling for years to render adequate care to our depressed patients. We often fail, even though we know that depression is common, painful, disabling, and expensive. ${ }^{1}$ We also know that there are adequate treatments available. Or are there? For over 2 decades investigators have been testing whether that's true, and by now the number of studies runs into the thousands. So this is a good time to pause and take stock. What do we know about the 2 fundamental modalities_-pharmacotherapy and psychotherapy — for treating depression in primary care? In this issue of the Annals, Linde et al present a pair of excellent metaanalyses that summarize and extend our current state

Conflicts of interest: author reports none.

\section{CORRESPONDING AUTHOR}

Frank V. deGruy, MD, MSFM

Department of Family Medicine

Mail stop F496 Academic Office 1

12631 East 17th Avenue

Aurora, CO

Frank.deGruy@ucdenver.edu of knowledge about the efficacy or effectiveness of these 2 categories of treatment for depression in the primary care setting. ${ }^{2,3}$ These results, and the studies on which they are based, can help us understand something about how to care for these patients, the persistent shortfalls in our care, and what we might do next about those shortfalls.

The studies that form the substrate for these 2 meta-analyses are themselves revealing. The analysis of pharmacological treatments includes 66 acceptable studies with 15,161 adult patients. ${ }^{2}$ These are the best of the randomized controlled trials comparing drugs of different classes to each other or to placebo. One-half of these studies have a high probability of bias of some sort, and another one-third are of uncertain bias status. In most of these studies the dosages are low, even below recommended dosages, and most are short-term trials of 24 weeks or less. Such is the state of pharmacotherapy trials in primary care: you could say this is a weak and messy set of studies. This collection of trials is not sufficient in number or quality to support many of the comparisons we might wish to make or to tell us with confidence which drugs are better for what, and how 
they should be used. But you could also say this is an elegant, state-of-the-art network meta-analysis, and certain interesting signals do emerge-more in the form of hints and probabilities than certainties. For example, there are no real differences in effectiveness across classes of drugs, and the differences in acceptability, if they exist at all, are hard to interpret. Forty percent of patients receiving placebo show a response-not remission-while $53 \%$ of those receiving (low doses of) active drugs respond. As the authors note, "effect sizes over placebo alone cannot provide information on the clinical relevance of treatment effects in individual clinical contexts, so that this issue is likely to remain controversial." ${ }^{\prime 2}$ Also, these are short-term data. And then there's the curious finding that St. John's wort seems to work better in German-speaking countries than other countries! Two things we can say with certainty are that we have not exhausted our need for well-done clinical trials in this field, and we do not yet have sufficiently effective pharmacotherapeutic agents for depression.

With respect to psychological treatments, less than one-half as many studies (30), and one-third as many patients $(5,159)$ were eligible for inclusion, and these studies, which are much harder to do well, are messier, more heterogeneous, and more non-comparable than even the pharmacotherapy trials. They are even more difficult to draw inferences from. Classifying treatments by type (eg, cognitive-behavioral therapy (CBT), interpersonal therapy, problem-solving therapy, etc), intensity, and mode of delivery (eg, face-to-face vs remote) necessarily produces difficult intraclass variation, mapping this against a range of diagnoses and severities, and comparing these to a heterogeneous set of usual care conditions (often unspecified) or placebo conditions-all of this creates a matrix of comparisons that is exceedingly "dirty," that begs for larger cells, clean distinctions, stable categories, and consistent definitions. To even further complicate the analysis, the risk of bias is either high or unknown in two-thirds of these studies, and 1 in 5 did not have major depression, but only minor depression or dysthymia. And yet again we have a careful and elegant meta-analysis, and a few provisional conclusions emerge. For example, all psychotherapies conducted face-to-face seem to work. Cognitive-behavioral therapy seems to work no matter how it's used, even at low intensity. None of these interventions appears to be effective for minor depression or dysthymia. In all cases, effect sizes are small: 10 patients must be treated to achieve 1 response, and 15 to achieve 1 remission.

Compare this to a recent meta-analysis of studies of treatment for depression in mental health care settings, where 182 studies enabled comparison of pharmacotherapies to each other, to placebo, and to psycho- therapies of various types. ${ }^{4}$ Among the many findings emerging from this larger dataset, we see moderate to large effect sizes of psychotherapies for almost every tested condition, especially CBT, exceeding that of pharmacotherapy.

We should not be misled into thinking that more trials of the kind analyzed here will give us all the knowledge we need to render consistently high-quality care. They will not. They will help (particularly if the quality of the trials is improved), but the knowledge we need for successful care of depressed patients goes beyond the efficacy or effectiveness of known drugs or psychotherapies. As we step back for a wide-angle look at this field, 2 additional considerations come into view. The first concerns psychotherapy itself, and the second concerns how we implement these treatments, however effective they may be, into the fabric of primary care.

Psychotherapies as described and practiced here are complex interventions that often consist of a linked set of several basic therapeutic modules or elements. There is compelling literature that suggests psychotherapy itself can be more flexibly and effectively applied, according to the needs of individual patients, if it is deconstructed into these basic modules or elements, which are then selected and combined into a personalized therapeutic strategy. ${ }^{5,6}$ Thus, we may soon see the emergence of a new unit of analysis and intervention for psychotherapy—psychotherapeutic "elements" that are simpler, more basic and generic, perhaps easier to master and measure. This could help clean up the problem we see in this present meta-analysis, where interventions of questionable comparability are pooled.

Implementation poses a more formidable set of issues. It is one thing to "know" that a psychotherapy is effective in primary care, when applied under research conditions, using study resources such as patient enrollment personnel, psychotherapists, and evaluators to assure that resource limitations or workflow barriers can be overcome. It is quite another thing for a primary care practice to implement such an evidencebased intervention using existing practice resources, working within the constraints of existing practice workflows, and pressing against the ubiquitous competing demands in these settings. Even the most powerful, desirable, and effective psychosocial interventions disrupt a practice's operations, and sometimes this disruption takes extraordinary time and resources to overcome. In fact, sometimes this disruption cannot be overcome, and the use of the intervention is impossible in a given setting at a given time. Thus, effective interventions are not useful until we know whether and how they can be implemented in real-world clinical settings. There is an emerging field of implementation science that addresses these issues. ${ }^{7}$ Successful implementation starts with an 
effective intervention, which is exactly where these 2 meta-analyses leave off, then takes into consideration factors associated with the patient, clinician, clinical setting, health plans, and regulators. We are becoming familiar with implementation issues in primary care as we attempt to transform our clinics to better manage patients' chronic diseases, to become patient-centered medical homes, to practice team-based care, or to continuously improve the quality of the care we render. We are learning through hard experience that even effective interventions or simple guidelines are not necessarily easy to implement in a busy primary care practice. This is not the place for a detailed description of the requirements of successful implementation, but it is the place to understand that well-done metaanalyses, such as those presented here, can not only summarize and clarify an emerging field, but can also set the stage for the implementation work that must inevitably follow before successful clinical improvement occurs in primary care.

To read or post commentaries in response to this article, see it online at http://www.annfammed.org/content/13/1/3.

Key words: depression; primary care; meta-analysis; implementation
Submitted October 13, 2014; accepted October 14, 2014.

\section{References}

1. Demyttenaere K, Bruffaerts R, Posada-Villa J, et al. Prevalence, severity, and unmet need for treatment of mental disorders in the World Health Organization World Mental Health Surveys. JAMA. 2004;291(21):2581-2590.

2. Linde K, Kriston L, Rücker G, et al. Efficacy and acceptability of pharmacological treatments for depressive disorders in primary care: systematic review and network meta-analysis. Ann Fam Med. 2015;13(1):69-79.

3. Linde K, Sigterman K, Kriston L, et al. Effectiveness of psychological treatments for depressive disorders in primary care: systematic review and meta-analysis. Ann Fam Med. 2015;13(1):56-68.

4. Huhn M, Tardy M, Spineli LM, et al. Efficacy of pharmacotherapy and psychotherapy for adult psychiatric disorders: a systematic overview of meta-analyses. JAMA Psychiatry. 2014;71(6):706-715.

5. Chorpita BF, Becker KD, Daleiden EL. Understanding the common elements of evidence-based practice: misconceptions and clinical examples. J Am Acad Child Adolesc Psychiatry. 2007;46(5):647-652.

6. Chorpita BF, Daleiden EL, Weisz JR. Identifying and selecting the common elements of evidence based interventions: a distillation and matching model. Ment Health Serv Res. 2005;7(1):5-20.

7. Proctor EK, Landsverk J, Aarons G, Chambers D, Glisson C, Mittman B. Implementation research in mental health services: an emerging science with conceptual, methodological, and training challenges. Adm Policy Ment Health. 2009;36(1):24-34. 